\section{Molecular Orientation of Fibres by Polarized Internal Reflexion Spectroscopy}

Successive drawing of synthetic fibres increases the molecular orientation of the polymer chains and is a method which is widely used for improving the tensile properties of yarns. Investigations of the changes in the dichroism of individual infra-red modes of the polymer with polarized infra-red radiation have yielded important conclusions regarding the structure and band assignments ${ }^{1}$. The dichroism of each infra-red mode, expressed as a dichroic ratio, is related to its transition moment; the angle of inclination of the bond to the molecular axis; and the degree of molecular orientation. Measurement of the dichroism of nylon fibres by infra-red transmission techniques has been introduced ${ }^{2}$ and questioned ${ }^{3}$ because sample preparation by microtoming can alter the existing orientation. Internal reflexion spectroscopy ${ }^{4}$, however, provides a non-destructive, rapid and reproducible method for obtaining the surface dichroism of any oriented fibre or film-measurements which are difficult or impossible to obtain by conventional transmission techniques.

An internal reflexion attachment ${ }^{5}$ was designed for use with commercial, double-beam spectrophotometers. A trapezoidal germanium prism, providing twenty-one internal reflexions, is placed at a focal point in each beam. Prism holders apply a known and constant hydraulic pressure against the sample and the prism surface to obtain sufficient and reproducible optical contact. A polished germanium reflexion polarizer $r^{6,7}$ is fixed in front of the monochromator entrance slit. Polarization efficiency in excess of 99 per cent is obtained with a single reflexion from the polarizer surface. First surface mirrors in the polarizer unit return the beam to the optical axis of the spectrophotometer.

To obtain the dichroic ratio, two infra-red spectra are obtained for each fibre at the same contact pressure. Initially, the fibres are placed against the surface of the internal reflexion prism with the incident electric vector parallel to the axis of the fibre. The fibres are then rotated through $90^{\circ}$ and the spectrum with perpendicular incidence is obtained. The dichroic ratio is calculated from the ratio of the absorption intensities for the parallel to perpendicularly polarized light at each infra-red mode.

The dichroic ratios for a series of drawn 66 nylon fibres at six frequencies are given in Table 1. The dichroic ratios for a pressed film were obtained for the draw ratio of unity. It was determined that the surface dichroic ratios obtained by internal reflexion spectroscopy are directly related to the bulk birefringence for fibres having a draw ratio of more than 1.4. For values of the draw ratio less than $1 \cdot 4$, the surface of the fibre appears to have greater orientation than the interior.

Table 1. DICHROIC RATIOS YOR A SERIES OF ORIENTED 66 NYLON FIBRES OBTAINED BY INTERNAL REFLEXION SPEOTROSCOPY AT VARIOUS INFRA-RED

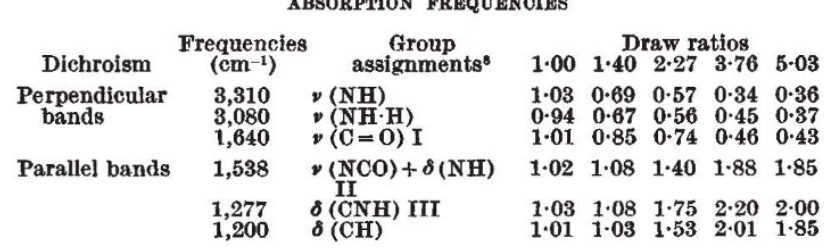

$\nu=$ stretching, $\delta=$ bending, in plane.

Quantitative polarization data obtained in this way are very sensitive to small changes in surface orientation at low draw ratios. The polarized internal reflexion technique therefore complements the X-ray diffraction method for measuring orientation-a method which is most useful for fibres of high molecular orientation. A satisfactory spectrum for each angle of polarization can be obtained without modification or deformation of the fibre, regardless of its diameter, surface condition, amount of dye or pigment content.

Engineering Physics Laboratory, J. K. BARR

Engineering Department,

E. I. du Pont de Nemours and Co., Inc.,

Wilmington,

Delaware.

Received April 24; revised July 24, 1967.

${ }^{1}$ Wilkinson, G. R., Price, W. C., and Bradbury, E. M., Spectrochim. Acta, 14, 284 (1959).

${ }^{2}$ Quynn, R. G., and Steele, R., Nature, 178, 1240 (1954).

"Caroti, G., and Dusenbury, J. H., J. Polymer Sci.,22, 399 (1956).

4 Wendlandt, W. W., and Hecht, H. G., Reflectance Spectroscopy (Interscience Publishers, New York, 1966).

${ }^{5}$ Flournoy, P. A., Spr. Meet., Opt. Soc. Amer., Washington, D.C. (March 1962).

- Edwards, D. F., and Bruemmer, M. J., J. Opt. Soc. Amer., 49, 860 (1959).

'Flournoy, P. A., and Shaffers, W. J., Spectrochim. Acta, 22, 15 (1966).

${ }^{8}$ Cannon, C. G., Spectrochim. Acta, 16, 302 (1960).

\section{THE SOLID STATE}

\section{Substitution by Iron in Kaolinite}

KAOLINITE often occurs in admixture with other minerals (for example, micas and iron oxides) in which iron is a legitimate constituent. Because of the difficulties of detection and separation, it has always been doubtful whether iron actually substitutes in the kaolinite lattice. We provide here evidence for substitution of iron(III) in the octahedral (Al) sites.

The materials studied were the fractions of two clays from the St. Austell area with equivalent spherical diameters of $1-2 \cdot 5 \mu$. These were subjected to repeated extraction in an inhomogeneous magnetic field as 16 per cent solid suspensions deflocculated at $p \mathrm{H} 8.0$ with 0.1 per cent $\mathrm{w} / \mathrm{w}$ tetrasodium phosphate.

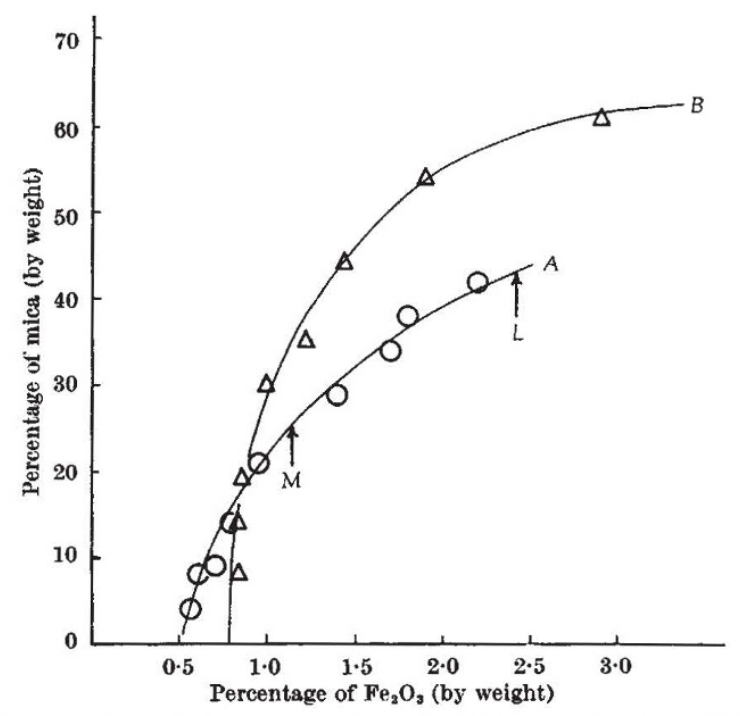

Fig. 1. Plot of the content of mica against the concentration of $\mathrm{Fe}_{2} \mathrm{O}_{3}$ for magnetic extracts of clay samples $A$ and $B$.

Fig. 1 shows a plot of the content of mica against the total content of iron (as $\mathrm{Fe}_{2} \mathrm{O}_{3}$ determined chemically) for those magnetic extracts of samples $A$ and $B$ which have been analysed. The contents of mica, tourmaline and felspar were deduced from X-ray powder photographs. A positive intercept on the abscissa is obtained for both clays, indicating that repeated extraction would yield a fraction containing no mica but 0.5 and 0.8 per cent $\mathrm{Fe}_{2} \mathrm{O}_{3}$ for $A$ and $B$ respectively. This residual iron is not extractable by acid washing. Chemical analysis of the highly refined specimens of $A$ and $B$ yields the following: 